\title{
Previous Exposure to THC Alters the Reinforcing Efficacy and Anxiety-Related Effects of Cocaine in Rats
}

\author{
Leigh V Panlilio', Marcello Solinas², Stephanie A Matthews' and Steven R Goldberg*,' \\ 'Department of Health and Human Services, Preclinical Pharmacology Section, Behavioral Neuroscience Branch, Intramural Research Program, \\ National Institute on Drug Abuse, National Institutes of Health, Baltimore, MD, USA; ${ }^{2}$ Laboratoire de Biologie et Physiologie Cellulaire, CNRS \\ 6187, University of Poitiers, Poitiers, France
}

\begin{abstract}
The hypothesis that prior cannabis exposure increases the likelihood of becoming addicted to other drugs can be evaluated by giving rats a history of tetrahydrocannabinol (THC) exposure, then allowing them to self-administer other drugs. In Experiment I, THC preexposure did not alter the acquisition of cocaine self-administration or the amount of cocaine taken under a fixed-ratio I (FR I) schedule, with one response required for each injection. Under a progressive-ratio schedule, with the response requirement increasing exponentially with each injection, cocaine-seeking was significantly reduced in $\mathrm{THC}$-exposed rats, suggesting that the regimen of $\mathrm{THC}$ exposure used in the present study caused cocaine to be devalued as a reinforcer. In contrast, in an earlier study that used the same regimen, a history of THC exposure did not alter the value of heroin as a reinforcer under the progressive-ratio schedule, but it increased heroin self-administration under the FRI schedule. Experiment 2 examined how this regimen of THC pre-exposure alters the locomotor effects of cocaine and heroin. THC pre-exposure produced cross-tolerance to the motor-depressant effects of heroin; this may explain the shortened post-injection pauses exhibited by THC-exposed rats under FRI heroin self-administration. When given cocaine, THCexposed rats exhibited normal increases in locomotion, but they avoided the center of the open field, suggesting that this THC preexposure regimen enhances the anxiogenic effects of cocaine. This enhanced anxiogenic effect — which was verified in Experiment 3 using another model of anxiety, the light-dark test-may explain the reduced reinforcing value of cocaine observed in THC-exposed rats in Experiment I.

Neuropsychopharmacology (2007) 32, 646-657. doi:I 0. I038/sj.npp. I 30 I I09; published online 3I May 2006
\end{abstract}

Keywords: self-administration; gateway drug hypothesis; progressive-ratio schedule; open field; light-dark test; heroin

\section{INTRODUCTION}

The possibility that cannabis use can increase the likelihood of becoming addicted to other drugs has long been debated, but there is still a need for objective evaluation of this 'gateway' hypothesis (Ellickson et al, 1992; Kandel, 1975; Kandel and Faust, 1975; Lynskey et al, 2003). Although supportive correlational evidence has been obtained (Fergusson and Horwood, 2000; Kandel, 2003), causal relationships between drug exposure and subsequent addiction are difficult to establish in humans because of the many historical, environmental, and social variables that cannot be controlled (Baumrind, 1983). Therefore, it has been

*Correspondence: Dr SR Goldberg, Preclinical Pharmacology Section, Behavioral Neuroscience Branch, Intramural Research Program, National Institute on Drug Abuse, NIH, DHHS, 5500 Nathan Shock Drive, Baltimore, MD 21224, USA, Tel: + I 410550 1522, Fax: + I 4I0 550 1648, E-mail: sgoldber@intra.nida.nih.gov

Received 6 December 2005; revised I8 April 2006; accepted 2 I April 2006

Online publication: 27 April 2006 at http://www.acnp.org/citations/ Npp0427060507/9/default.pdf suggested that experiments using animal models of drug abuse may provide the best means of testing the gateway hypothesis (Kandel, 2003).

To this end, we recently evaluated the effects of tetrahydrocannabinol (THC) exposure on subsequent selfadministration of heroin in rats (Solinas et al, 2004). Using a regimen of THC pre-exposure that had earlier been shown to enhance the locomotor-activating effects of THC or morphine (Cadoni et al, 2001), rats were injected six times with THC or vehicle over 3 days. Beginning 1 week after the last injection of THC, rats were tested for acquisition of heroin self-administration under a fixed-ratio 1 (FR1) schedule, in which only one response is required for each injection. THC exposure did not affect the likelihood of acquiring the heroin self-administration response, but THC-exposed rats took significantly more heroin injections per session than vehicle-exposed rats. Next, a progressiveratio schedule (see Arnold and Roberts, 1997; Griffiths et al, 1975; Stafford et al, 1998) was instituted to assess the reinforcing efficacy of self-administered heroin in the same rats. Under this schedule, the response requirement increases exponentially with each successive injection. The 
behavior of THC-exposed and vehicle-exposed rats did not differ under the progressive-ratio schedule, indicating that THC pre-exposure did not alter the reinforcing efficacy of heroin (Solinas et al, 2004). Thus, these results suggest that individuals with a history of THC exposure might take heroin more frequently if it were freely available, but they would not work harder than non-exposed individuals to obtain heroin if the cost were increased.

A number of previous studies have demonstrated that cannabinoid ligands can modulate the reinforcing effects (Caille and Parsons, 2003; DeVries et al, 2003; Navarro et al, 2001; Norwood et al, 2003; Solinas et al, 2003, 2005) and locomotor effects (Cadoni et al, 2001; Lamarque et al, 2001; Pontieri et al, 2001; Rubino et al, 2003) of opioid agonists. In the case of psychomotor stimulants, there is some evidence that exposure to THC or cannabinoid agonists may lead to behavioral sensitization with amphetamine (Gorriti et al, 1999; Lamarque et al, 2001). In addition, it has recently been reported that one (Gorriti et al, 2005) or several (Moreno et al, 2005) injections of cannabinoid agonists render rats more sensitive to the effects of direct dopamine receptor agonists. Several studies have examined the ability of pharmacological or genetic blockade of cannabinoid receptors to alter the behavioral effects of cocaine (Caille and Parsons, 2003; Cossu et al, 2001; Martin et al, 2000; Soria et al, 2005; Tanda et al, 2000). For example, acute administration of the CB1 receptor agonist WIN55,202-5 can decrease cocaine self-administration (Fattore et al, 1999), and mice lacking the CB1 receptors show reduce reinforcing efficacy of cocaine (Soria et al, 2005). On the other hand, others have found that administration of the cannabinoid $\mathrm{CB} 1$ receptor antagonist rimonabant (SR141716A) did not affect self-administration of cocaine in squirrel monkeys (Tanda et al, 2000) or rats (Caille and Parsons, 2003) and that mice lacking the CB1 receptor show normal cocaine reinforcement in selfadministration and conditioned place preference paradigms (Cossu et al, 2001; Martin et al, 2000). However, there have been no studies to our knowledge that have assessed the validity of the gateway hypothesis in experimental animals by determining whether a history of THC exposure affects the subsequent self-administration of cocaine.

Thus, to determine whether a history of THC preexposure alters the reinforcing effects of cocaine, we applied the same general procedure used earlier to study heroin self-administration (Solinas et al, 2004). Thus, in Experiment 1, rats were exposed to THC or vehicle for 3 days, ending 1 week before they were trained to self-administer cocaine under an FR1 schedule. They were then tested under a progressive-ratio schedule over a range of doses of cocaine. Experiment 2 evaluated whether a history of THC exposure would alter the locomotor effects of cocaine or heroin in an open field. Starting 1 week after the last THC exposure, measures were taken of both general locomotor activity and entries into the center of the field, a measure that has recently been reported to reveal anxiety-related effects of cocaine (Carey et al, 2005a, b; see also Ramos et al, 1998, 2003; Vendruscolo et al, 2003). Anxiety-related effects observed in Experiment 2 were confirmed and extended in Experiment 3 using the light-dark test, a different animal model of anxiety (Costall et al, 1989a; Hascoët and Bourin, 1998; Onaivi and Martin, 1989; Pich and Samanin, 1989).

\section{MATERIALS AND METHODS}

\section{Subjects}

Experimentally naive Sprague-Dawley rats (Charles River, Wilmington, MA, USA) were 3-4 months old and weighed $300-325 \mathrm{~g}$ at the start of the study. Rats were individually housed in a temperature- and humidity-controlled room on a 12-h light/dark cycle. Experiments were conducted during the light phase. Water was available on an ad libitum basis in the home cage, and laboratory chow was provided in an amount (15-20 g/day) that maintained approximately constant body weights throughout the experiment. The total numbers of rats used in each experiment were 30 in Experiment 1, 31 in Experiment 2, and 39 in Experiment 3. All rats in Experiment 1 (self-administration) were used only in that experiment. Rats tested with heroin in Experiment 2 (open-field test) were used only in that experiment. The 15 rats that received cocaine in Experiment 2 (open-field test) were also tested subsequently with cocaine in Experiment 3 (light-dark test), and 24 additional, experimentally naive rats were also studied in Experiment 3. The facilities were fully accredited by the American Association for the Assessment and Accreditation of Laboratory Animal Care. All procedures were approved by the Institutional Care and Use Committee of the Intramural Research Program, National Institute on Drug Abuse (NIDA) and conducted in accordance with the Guidelines for the Care and Use of Mammals in Neuroscience and Behavioral Research (National Research Council, 2003).

THC pre-exposure. In each experiment, rats were randomly divided into two groups. THC-exposed rats received intraperitoneal (i.p.) injections of THC twice a day for 3 days. The dose of THC was $2 \mathrm{mg} / \mathrm{kg} /$ injection on the first day, $4 \mathrm{mg} / \mathrm{kg} /$ injection on the second day, and $8 \mathrm{mg} / \mathrm{kg} /$ injection on the third day. Vehicle-exposed rats received an injection of an equivalent volume of vehicle. This level of THC pre-exposure has been shown to enhance the locomotor-activating effects of THC as well as morphine (Cadoni et al, 2001), and it is also the same regimen used in our earlier study examining the effects of THC pre-exposure on subsequent heroin self-administration (Solinas et al, 2004).

\section{Experiment 1: Cocaine Self-Administration}

Catheterization. One day after the last THC or vehicle injection, rats in Experiment 1 were implanted with catheters in the right jugular vein under aseptic conditions using i.p. ketamine $(60 \mathrm{mg} / \mathrm{kg})$ and xylazine $(10 \mathrm{mg} / \mathrm{kg})$ anesthesia as previously described (Solinas et al, 2003). When rats developed a blocked catheter in an advanced phase of the experiment, a second catheter was implanted in the left jugular vein. During experimental sessions, the catheter was connected to an injection pump (Med Associates, St Albans, VT, USA) that delivered cocaine solution $(3 \mathrm{mg} / \mathrm{ml})$ from a $10-\mathrm{ml}$ syringe at a rate of $3.19 \mathrm{ml} /$ min through tubing passed through a metal spring. Catheters were flushed before and after each session with $0.1 \mathrm{ml}$ of saline solution. 
Cocaine self-administration apparatus. Experimental chambers $(30 \times 24 \times 29 \mathrm{~cm}$; Coulbourn Instruments, Allentown, PA) enclosed in sound-attenuation chests had a metal grid floor. On one wall, there were two nose-poke holes, with a shielded white light and a speaker in the center of the wall, above the holes. The light was illuminated at all times except during injection and time-out periods, when the light and a $4500 \mathrm{~Hz}$ tone were pulsed at a rate of $5 \mathrm{~Hz}$ with one stimulus on while the other was off. Experimental events were controlled by microcomputers using Med Associates interfaces and software (Med Associates, East Fairfield, VT, USA).

\section{Cocaine self-administration procedure.}

Fixed-ratio 1 schedule: Self-administration sessions under an FR1 schedule began 1 week after the last i.p. THC or vehicle injection. During 3-h daily sessions, a single response in the left nose-poke hole (the active hole) immediately delivered an intravenous (i.v.) injection of cocaine $(0.3 \mathrm{mg} / \mathrm{kg} /$ injection $)$ and caused the house light and tone to pulse for $5 \mathrm{~s}$. During this 5 -s time-out period, responding had no programmed consequences. Responses in the nose-poke hole on the right side (the inactive hole) were recorded but had no programmed consequence. Acquisition of self-administration responding was evaluated over 10 consecutive sessions. The criterion for cocaine selfadministration was met if a rat obtained at least 10 cocaine injections in each of the last three sessions. Rats that selfadministered less than 10 injections during the eighth session but 10 or more injections during the ninth and tenth sessions were trained for one additional session (11 total sessions). Data collected under the FR1 schedule included the number of injections per session and the number of nose-pokes per session in the active and inactive holes (including reinforced responses and responses during injections and time-out periods). After the FR1 phase, rats that met the criterion for acquisition of cocaine selfadministration were sequentially switched to (1) a variabledose schedule for two sessions, (2) a progressive-ratio schedule for a total of eight sessions, (3) back to the FR1 schedule for two sessions, and finally (4) back to the variable-dose schedule for two sessions. One rat in the THC-exposed group that had met the acquisition criterion but had not been tested under the progressive-ratio schedule was dropped from the study because of catheter failure. Eleven rats in each group completed all phases of Experiment 1.

Variable-dose schedule of cocaine self-administration: This schedule was used to rapidly obtain a dose-effect curve for cocaine under the FR1 schedule. The dose per injection was manipulated from injection to injection by varying the duration of syringe-pump activation (approximately 0.5$2 \mathrm{~s})$. Three different doses of cocaine $(0.1,0.3$, and $1.0 \mathrm{mg} /$ $\mathrm{kg}$ ) were made available in a pseudo-random order, with a total of 24 injections available per session. After the first two injections, which were always $0.3 \mathrm{mg} / \mathrm{kg}$ and were not included in the analysis, the doses were arranged as four sets of six injections. Within each set, doses were determined by sampling without replacement from a list in which each dose occurred twice. The primary datum was the amount of time between consecutive injections. This latency measure (ie, the inter-injection interval or postinjection pause) typically varies as a direct function of dose, allowing a dose-effect curve to be obtained within a single session (Gerber and Wise, 1989; Panlilio and Schindler, 2000; Solinas et al, 2004). Data were analyzed for the second of the two variable-dose sessions before the progressiveratio phase of Experiment 1 and also for the second of the two variable-dose sessions after the progressive-ratio phase.

Progressive-ratio schedule of cocaine self-administration: Under this schedule, the response requirement increased exponentially with each successive injection. The progression of response requirements was the same as those previously described in our parallel study with heroin (Solinas et al, 2004). Sessions ended after $30 \mathrm{~min}$ had passed without a response; on the rare occasion that this did not occur, the session ended after $5 \mathrm{~h}$. Rats were initially trained for two sessions under this schedule with a cocaine dose of $0.3 \mathrm{mg} / \mathrm{kg} /$ injection, but these data were not included in the analysis. Then, they were given two consecutive sessions at each of three different doses of cocaine in the following order: $0.3,0.3,0.1,0.1,1.0$, and $1.0 \mathrm{mg} / \mathrm{kg} /$ injection. Response rate data, including all responses emitted during the session, were averaged for the two sessions at each dose.

\section{Experiment 2: Locomotor Activity in the Open Field}

Locomotor activity apparatus. Locomotor chambers (Med Associates, East Fairfield, VT, USA) were enclosed in sound-attenuation chests, with two chambers in each chest. Chambers $(41 \times 41 \times 32 \mathrm{~cm})$ were composed of clear acrylic and had sawdust bedding on the floor. Eight chambers were used in both the cocaine and heroin studies. However, data for the heroin study were lost from two of the chambers (including two rats from each heroin group) because of an equipment failure. Activity was measured with a $16 \times 16$ array of photobeams. Med Associates Open Field Activity Software recorded the distance traveled during the session and the number of entries into an unmarked square (defined by the software) in the center of the field ('center zone'), covering one-ninth of the total area. No illumination was provided when the chamber was closed. Four groups were tested: a THC-exposed group tested with cocaine $(n=7)$; a vehicle-exposed group tested with cocaine $(n=8)$; a THC-exposed group tested with heroin $(n=6)$; and a vehicle-exposed group tested with heroin $(n=6)$.

Locomotor activity procedure. To determine whether THC exposure alters baseline levels of locomotor activity, two 30 min locomotor sessions were conducted: the first was 1 day before THC or vehicle exposure was started, and the second was 1 week after exposure had ended. In each of the next 10 sessions, cocaine $(20 \mathrm{mg} / \mathrm{kg})$ or heroin $(1 \mathrm{mg} / \mathrm{kg})$ was injected i.p. immediately before the rat was placed in the chamber for $30 \mathrm{~min}$ (cocaine) or $3 \mathrm{~h}$ (heroin). These i.p. doses of cocaine and heroin are within the range commonly used in studies of locomotor sensitization and conditioned place preference. These drug sessions were conducted Monday-Friday for 2 weeks, for a total of 10 sessions. 


\section{Experiment 3: Light-Dark Test}

Light-dark test apparatus. Four clear acrylic shuttle boxes (MED-Associates, model ENV-010MC) were individually enclosed in sound-attenuation chests in a darkened room illuminated only by the screen of the computer. Shuttle boxes measured $40 \times 16 \times 21 \mathrm{~cm}$ and had an opaque black wall $(2.5 \mathrm{~cm}$ thick) with a doorway (measuring $9 \times 12 \mathrm{~cm}$ ) between the compartments, such that the lighted compartment was $20 \mathrm{~cm}$ long and the dark compartment was $17.5 \mathrm{~cm}$ long. One compartment was lit by a light bulb $(100 \mathrm{~mA}, 28 \mathrm{~V})$ covered by a white lens on the center of the wall at the far end of the compartment, $14.5 \mathrm{~cm}$ above the floor. The other compartment was unlit and had an opaque black covering around the outside of the box. The illuminance (measured with a Sekonic light meter, model L308-B) was approximately 2600 lux in the light side (directly in front of the light) and approximately 5 lux in the dark side (facing the doorway). Each compartment had four photobeams spaced $5 \mathrm{~cm}$ apart, starting $5 \mathrm{~cm}$ from the center of the box. The rat was considered to be in a specific compartment once it broke the third or fourth beam in that compartment. The rat was considered to be between the compartments (ie, part in the light and part in the dark) when it broke the first or second beam of the other compartment; once the rat was between compartments, it was not considered to be entirely in one compartment or the other until it broke the third or fourth beam of that compartment. Locomotion was measured as the number of activity counts (ie, beam breaks), excluding consecutive, repeated breaks of the same beam.

Light-dark test procedure. The two groups of rats (THCexposed and vehicle-exposed) that had been tested with cocaine in the locomotor chamber in Experiment 2 were also tested with cocaine $(20 \mathrm{mg} / \mathrm{kg})$ in the light-dark test in Experiment 3; this light-dark test was conducted 3 months after their 3-day exposure to THC or vehicle. In addition, four new groups of rats were given the light-dark test in Experiment 3: a THC-exposed group tested with cocaine $(n=6)$; a THC-exposed group tested with saline $(n=6)$; a vehicle-exposed group tested with cocaine $(n=6)$; and a vehicle-exposed group tested with saline $(n=6)$. These rats were tested 1 week after THC or vehicle exposure. On the day of the test, rats were transported to the darkened room and left in their home cages for at least $1 \mathrm{~h}$. Rats were then injected with saline or $20 \mathrm{mg} / \mathrm{kg}$ cocaine and returned to their home cages for $15 \mathrm{~min}$ before testing. To start the test, a rat was placed in the light compartment, facing the corner of the wall with the light. Two measures were taken during the 5-min test: (1) percentage of time spent in the light compartment, not counting time spent between the compartments; and (2) the level of activity in counts/min.

\section{Drugs}

$\Delta$-9-THC (National Institute on Drug Abuse, Baltimore, $\mathrm{MD}$, USA), $50 \mathrm{mg} / \mathrm{ml}$ in ethanol, was dissolved in a $40 \% \mathrm{w} / \mathrm{v}$ solution of cyclodextrin (RBI/SIGMA, Natick, MA, USA). THC was given i.p. in a volume of $2 \mathrm{ml} / \mathrm{kg}$ for the doses of 2 and $4 \mathrm{mg} / \mathrm{kg}$ and in a volume of $4 \mathrm{ml} / \mathrm{kg}$ for the $8 \mathrm{mg} / \mathrm{kg}$ dose because of solubility constraint. Ethanol concentrations in
THC solutions were between 2 and $4 \% \mathrm{v} / \mathrm{v}$. Corresponding amounts of ethanol were added to vehicle solutions. Cocaine and heroin (National Institute on Drug Abuse, Baltimore, MD, USA) were dissolved in saline solution and distilled water, respectively, and were given in a volume of $1 \mathrm{ml} / \mathrm{kg}$ when injected i.p.

\section{Data Analysis}

Data were analyzed using Proc Mixed (SAS Institute, Cary, NC). Paired comparisons were conducted using the TukeyKramer procedure with a 0.05 significance level for each set of tests. For the acquisition phase of Experiment 1, response rates were analyzed with pre-exposure (THC-exposed $v s$ vehicle-exposed), session number (1-10), and response type (active $v s$ inactive hole) as factors. For the variable-dose schedule, response latencies (inter-injection intervals) for the active hole were analyzed with pre-exposure, session (before $v s$ after the progressive-ratio phase of the study), and dose of cocaine as factors. For the progressive-ratio schedule, response rates were analyzed with pre-exposure, dose of cocaine, and response type as factors. For Experiment 2, distance traveled and the number of centerzone entries were analyzed with pre-exposure (THC vs vehicle) and session number (1-10) as factors. For heroin, each 3 -h session was divided into 30 -min periods, so an additional factor (time in session) was included in the analysis. For Experiment 3, the percentage of time spent in the light compartment and the level of locomotor activity were analyzed. For the two groups of rats in Experiment 3 that had previously been exposed to cocaine in Experiment 2 , data from the light-dark test were analyzed using Student's $t$-test. For the four groups of rats tested only in Experiment 3, data were analyzed as a $2 \times 2$ factorial design, with pre-exposure (THC vs vehicle) and acute treatment (cocaine $v s$ saline) as factors.

\section{RESULTS}

\section{Experiment 1: Cocaine Self-Administration}

Acquisition of cocaine self-administration. Pre-exposure to THC did not affect the acquisition of cocaine selfadministration. Figure 1 shows that response and injection rates were similar for both THC-exposed and vehicleexposed rats throughout training. Statistical analysis of response rates confirmed that there were no significant main or interaction effects involving THC exposure $(p$ 's $>0.6)$. The interaction of response type and session was significant $(\mathrm{F}(9,399)=2.28, p<0.05)$, with response rates for both groups significantly higher in the active hole than the inactive hole during the ninth and tenth sessions. The proportion of rats meeting the acquisition criterion was similar in both groups (THC-exposed: 12/15; vehicleexposed: 11/15).

Variable-dose schedule of cocaine self-administration. Pre-exposure to THC also did not affect the cocaine doseeffect functions obtained with the variable-dose schedule (see Figure 2). There were no significant main or interaction effects involving THC exposure ( $p$ 's $>0.5)$. Response latencies increased monotonically as a function of dose 

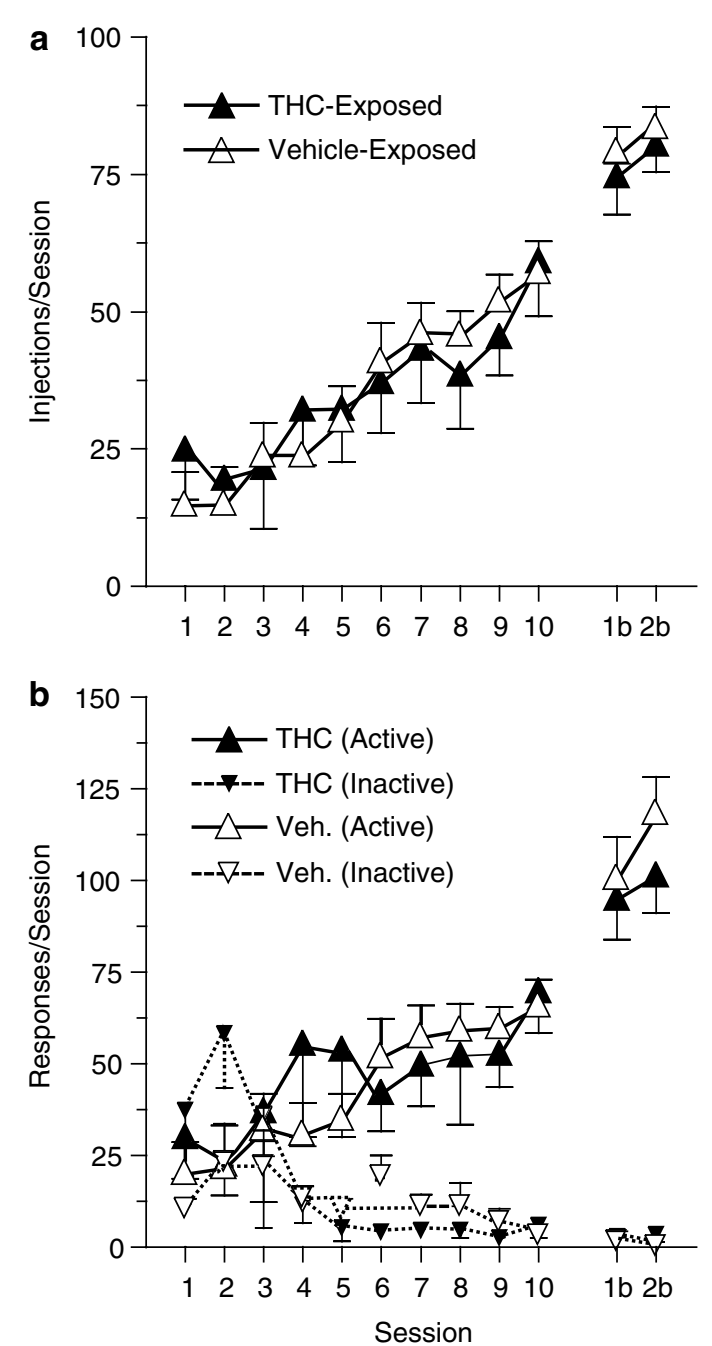

Figure I Acquisition of cocaine self-administration under the FR I schedule at a dose of $0.3 \mathrm{mg} / \mathrm{kg} /$ injection in Experiment I. (a) Injections/ session (mean \pm SEM). (b) Responses/session in the active (solid lines) and inactive (dashed lines) nose-poke holes. Data for each session include all rats that met the acquisition criterion by the end of FRI training. Data are also shown for the two FRI sessions (' $I b$ ' and ' $2 b$ ') that followed testing with the progressive-ratio schedule. Filled triangles: THC-exposed rats; open triangles: vehicle-exposed rats. There were no significant differences between the THC- and vehicle-exposed groups during acquisition. Note that in all figures, error bars not seen are covered by the symbol.

per injection, with latencies at each dose significantly different from each other dose $(p$ 's $<0.05)$. When doseeffect curves from the variable-dose procedure were compared before and after the rats were trained with the progressive-ratio schedule, it was found that latencies for the two higher doses of cocaine had become shorter, but this shift was equivalent in THC- and vehicle-exposed rats. Thus, the interaction of dose and session (variable-dose sessions before $v s$ after the progressive-ratio phase) was significant $(\mathrm{F}(2,94)=7.97, p<0.05)$, with latencies for the highest dose of cocaine becoming significantly shorter $(p<0.05)$ in the later session, indicating more rapid intake.

Progressive-ratio schedule of cocaine self-administration. THC-exposed rats emitted fewer responses and took fewer injections of cocaine than vehicle-exposed rats under the

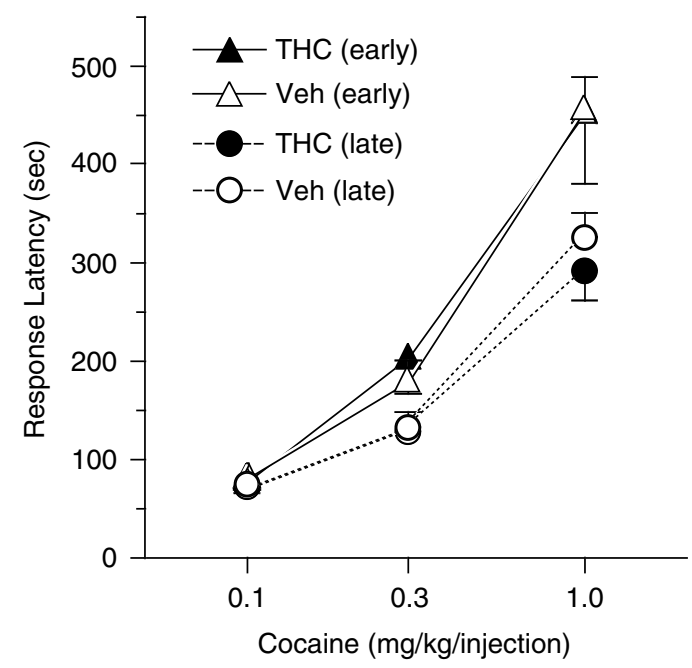

Figure 2 Within-session dose-effect curves under the variable-dose schedule of cocaine self-administration in Experiment I. Mean ( \pm SEM) response latencies following the three doses of cocaine are shown. Data are shown for the variable-dose sessions early in training (before testing with the progressive-ratio schedule; triangles, solid lines) and late in training (after testing with the progressive-ratio schedule; circles, dashed lines). Filled symbols: THC-exposed rats; open symbols: vehicle-exposed rats. Latencies were dose-dependent in both groups, and latencies following the highest dose of cocaine were significantly shorter in late vs early training, but there were no significant differences between the THC- and vehicleexposed groups under this schedule.

progressive-ratio schedule (see Figure 3). The interaction of response type and group was significant $(\mathrm{F}(1,100)=4.38$, $p<0.05$ ), with THC-exposed rats emitting significantly fewer responses than vehicle-exposed rats in the active hole. This responding was dose-dependent within each group, with each dose differing significantly from each other dose $(p$ 's $<0.05)$. THC-exposed and vehicle-exposed rats did not differ in their inactive-hole responding $(p>0.9)$.

\section{Experiment 2: Locomotor Activity in the Open Field}

Locomotor effects of cocaine. Pre-exposure to THC did not affect baseline levels of locomotion or center-zone entry, either within subjects (before $v s$ after pre-exposure) or between groups (THC $v s$ vehicle; all $p$ 's $>0.9$ ). Figure $4 \mathrm{a}$ shows that THC-exposed and vehicle-exposed rats exhibited similar levels of locomotor activity when given cocaine. Although these levels of activity were slightly lower on average in THC-exposed rats, there was considerable overlap in the two groups, and they did not differ significantly (main effect of pre-exposure: $p>0.25$; interaction of pre-exposure and session number: $p>0.65$ ). Overall, distance traveled increased gradually over successive cocaine sessions. The main effect of session number was significant $(\mathrm{F}(9,117)=3.29, p<0.01)$, and distance traveled during the ninth session was significantly longer than in the first, fourth, and fifth cocaine sessions $(p$ 's $<0.05)$. Thus, pre-exposure to THC did not alter the initial effects of cocaine or the development of sensitization to the effects of cocaine on distance traveled. In contrast to this lack of effect on general activity, THC exposure did have a 

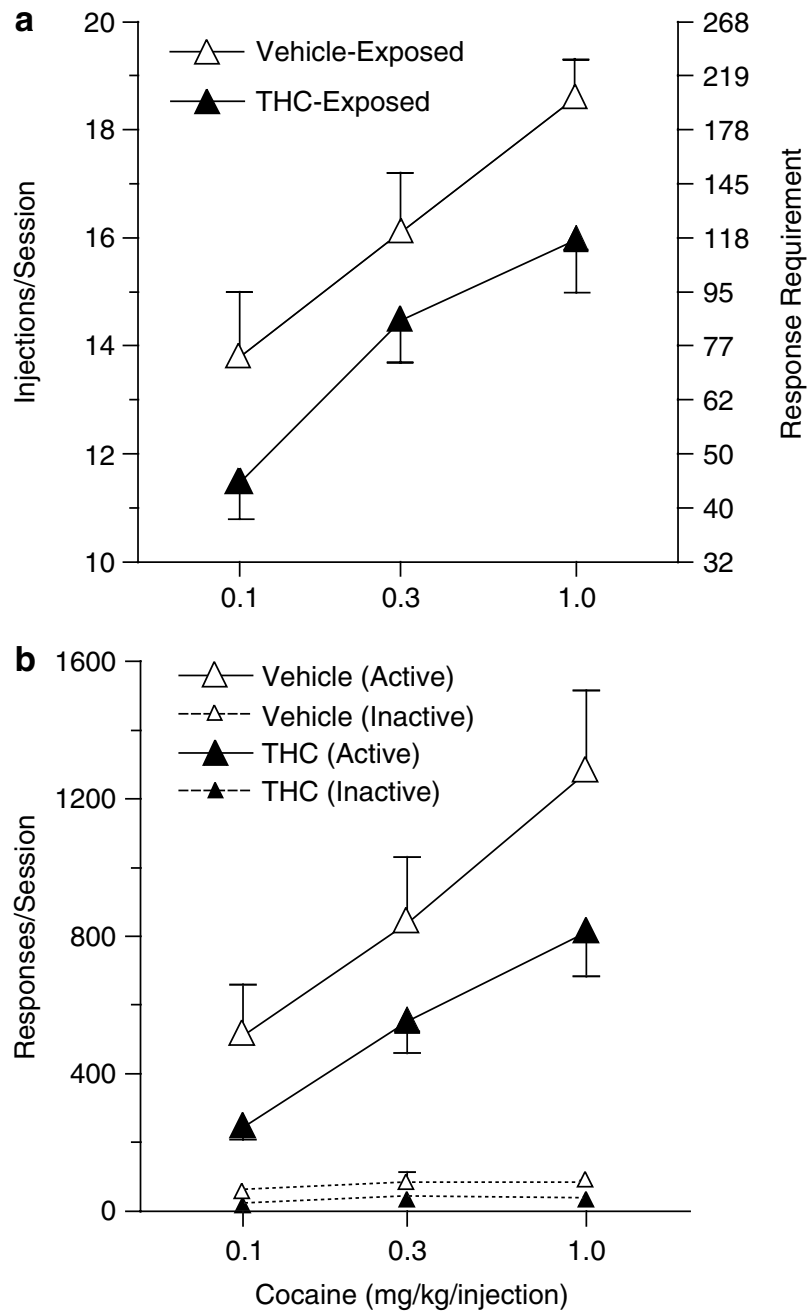

Figure 3 Performance under the progressive-ratio schedule of cocaine self-administration in Experiment I. (a) Injections/session (mean \pm SEM; left axis) and the corresponding response requirement (right axis) for the three doses of cocaine. Note that $y$-axis does not start at zero. (b) Responses/ session in the active (solid lines) and inactive (dashed lines) nose-poke holes. Filled triangles: THC-exposed rats; open triangles: vehicle-exposed rats. Under this schedule, active-hole responding was significantly reduced in THC-exposed rats.

profound effect on the number of entries into the center of the field. Figure $4 \mathrm{c}$ shows that cocaine significantly elevated the number of center-zone entries in vehicle-exposed rats, but this effect was virtually eliminated in THC-exposed rats. Center-zone entries did not show sensitization over the 10 cocaine sessions. The main effect of pre-exposure on centerzone entries was significant $(\mathrm{F}(1,13)=5.56, p<0.05)$, but there was no significant effect of session number $(p>0.98)$ or the interaction of session number and pre-exposure $(p>0.72)$.

Locomotor effects of heroin. THC-exposed rats exhibited significantly higher levels of activity than vehicle-exposed rats during the first $30 \mathrm{~min}$ after receiving heroin (Figures $4 \mathrm{~b}$ and 5). This group difference was maintained across the 10 sessions of testing with heroin. Locomotion in THCexposed rats tended to be highest during the first 30-min period, and it declined monotonically for the remainder of the session. Locomotion in vehicle-exposed rats tended to be low at the beginning of the session, then increased to near or slightly above the levels in THC-exposed rats during the middle periods of the session, and finally decreased during the final two periods. For distance traveled, the interaction of pre-exposure and time within the session was significant $(\mathrm{F}(5,406)=10.35, p<0.0001)$, and paired comparisons indicated that THC-exposed rats had significantly higher levels of activity than vehicle-exposed rats during the first $30 \mathrm{~min}(p<0.05)$. With regard to center-zone entries (Figures $4 \mathrm{~d}$ and 6 ), THC-exposed rats showed significantly more entries than vehicle-exposed controls (mean \pm $\mathrm{SEM}=129.9 \pm 16.0$ entries/session $v s \quad 81 \pm 10.0$, respectively), an effect opposite to that observed with cocaine. For center-zone entries, the only significant effect was the main effect of pre-exposure $(\mathrm{F}(1,14)=6.49, p<0.05)$. Heroin's effects on center-zone entries and distance traveled showed different time courses. While THC-exposed rats showed the highest levels of activity during the first $30 \mathrm{~min}$ after receiving heroin, center-zone entries were highest during the middle of the session in these rats. Thus, increased entries into the center zone when the THCexposed group was given heroin were not a simple byproduct of their higher levels of locomotor activity. This dissociation between distance traveled and center-zone entries during heroin treatment is confirmed by the low correlation between the two measures in rats given heroin $(r=0.073)$. A higher correlation was observed in rats given cocaine $(r=0.48)$.

\section{Experiment 3: Light-Dark Test}

The results obtained with cocaine in the light-dark test in Experiment 3 were consistent with the findings obtained with the open-field test in Experiment 2, suggesting that THC pre-exposure enhanced cocaine's anxiogenic effects without significantly altering its general locomotor effects. When the rats that had previously received cocaine in the locomotor chamber during Experiment 2 were given cocaine and tested in the light-dark test in Experiment 3 (see Figure 7), the THC-exposed group spent significantly less time in the lighted compartment $(\mathrm{t}(13)=2.58, p<0.05)$, consistent with an anxiogenic effect. These two groups did not differ in locomotor activity during the light-dark test $(p>0.74)$. In the four groups of rats that were tested only in Experiment 3 (see Figure 8), THC pre-exposure $(\mathrm{F}(1,44)=4.02, \quad p<0.05)$ and acute cocaine exposure $(\mathrm{F}(1,44)=6.48, p<0.05)$ each produced a decrease in time spent in the lighted compartment, but paired comparisons revealed that this measure was only significantly affected (suggesting an anxiogenic effect) in one group, the THCexposed rats that were given cocaine $(p<0.05)$. Cocaine significantly increased locomotor activity in both the THCexposed and vehicle-exposed groups ( $p$ 's $<0.05)$.

\section{DISCUSSION}

The regimen of THC pre-exposure used in this study did not affect the likelihood of rats acquiring cocaine selfadministration, nor did it affect their rates of cocaine taking 

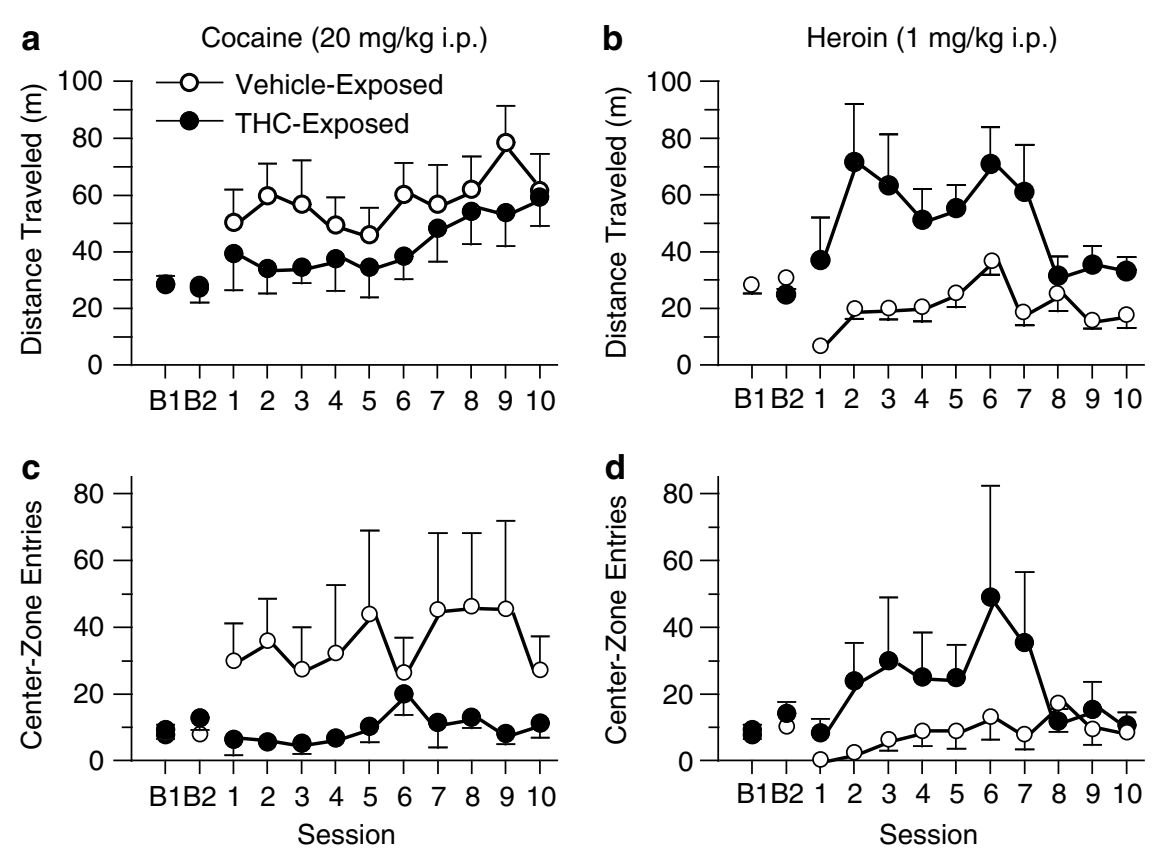

Figure 4 Locomotor activity and center-zone entries of THC- and vehicle-exposed rats tested with cocaine $(20 \mathrm{mg} / \mathrm{kg})$ or heroin (I mg/kg) in Experiment 2. Upper panels show mean ( \pm SEM) distance traveled $(m)$ in 30 min during the first baseline session ('BI', before THC exposure, with no injection before the locomotor session), during the second baseline session ('B2', I week after THC exposure, with no injection before the locomotor session), and during each of 10 sessions in which cocaine (a) or heroin (b) was injected immediately before the session. Cocaine sessions and baseline sessions ended after $30 \mathrm{~min}$. Heroin sessions ended after $3 \mathrm{~h}$ (see Figures 5 and 6), but data from the first $30 \mathrm{~min}$ are presented here for comparison with cocaine. Lower panels show mean $( \pm S E M)$ number of center-zone entries during the same sessions for cocaine (c) and heroin (d). When cocaine was administered, THC- and vehicle-exposed rats did not differ in distance traveled, but THC-exposed rats made significantly fewer entries into the center zone.
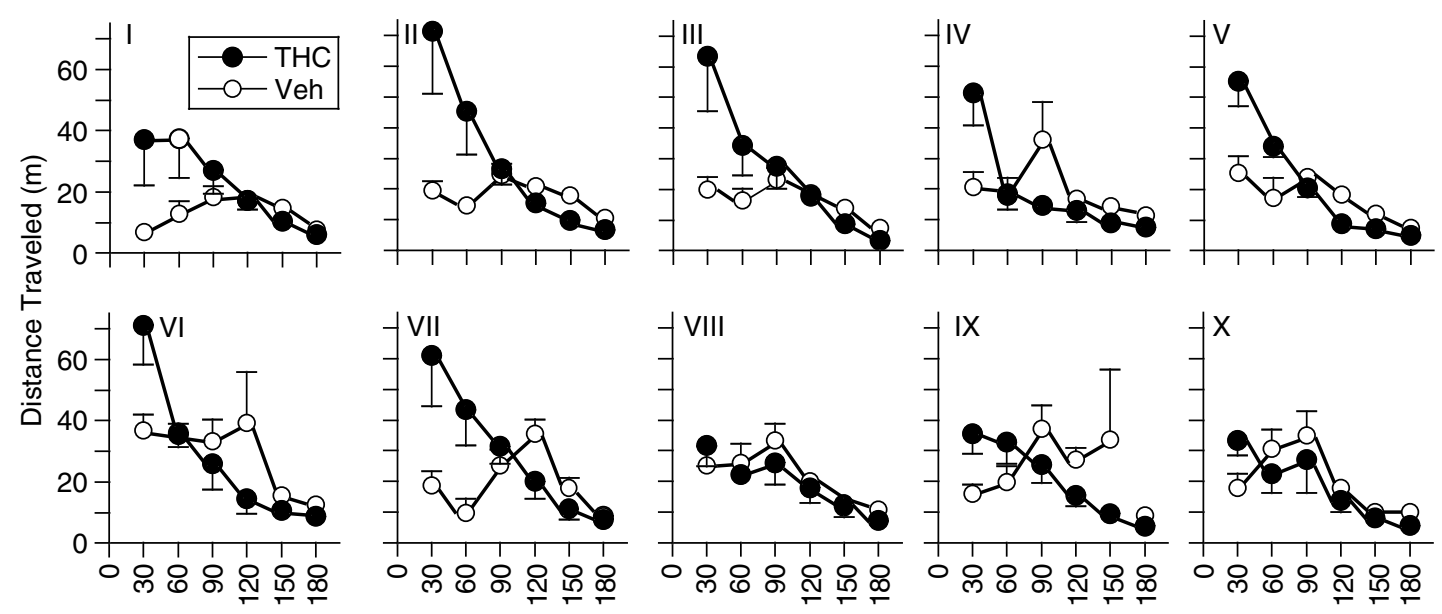

\footnotetext{
Time in Session (Minutes)
}
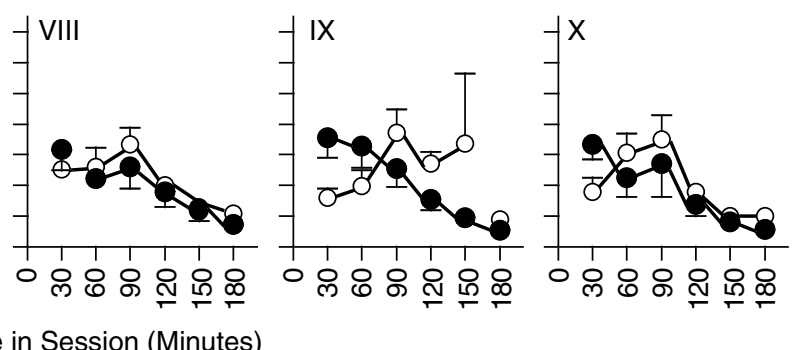

Figure 5 Locomotor activity of THC- and vehicle-exposed rats tested with heroin in Experiment 2. Mean ( \pm SEM) distance traveled $(\mathrm{m})$ during each of 10 sessions in which cocaine was injected immediately before the session are shown. Each session lasted $3 \mathrm{~h}$, and data were analyzed in 30-min periods. Roman numerals: session number; filled circles: THC-exposed; open circles: vehicle-exposed. During the first 30 min after heroin was administered, THCexposed rats had significantly higher levels of activity than vehicle-exposed rats.

under the FR1 schedule. However, the reinforcing efficacy of cocaine was reduced in THC-exposed rats, as indicated by the fact that they emitted significantly fewer 'cocaineseeking' responses than THC-naive rats under the progressive-ratio schedule. These results contrast sharply with our previous study of heroin self-administration, where the same regimen of THC pre-exposure increased the rate of heroin taking under FR1 but had no effect on heroin's reinforcing efficacy under the progressive-ratio schedule (Solinas et al, 2004). Although the use of a single dosage regimen of THC in these studies may limit the generality of their conclusions, these results clearly indicate that (1) THC exposure can produce long-lasting alterations in the behavioral effects of cocaine and heroin and (2) these alterations can be quite different with heroin $v s$ cocaine, but (3) THC exposure does not appear to increase the likelihood 


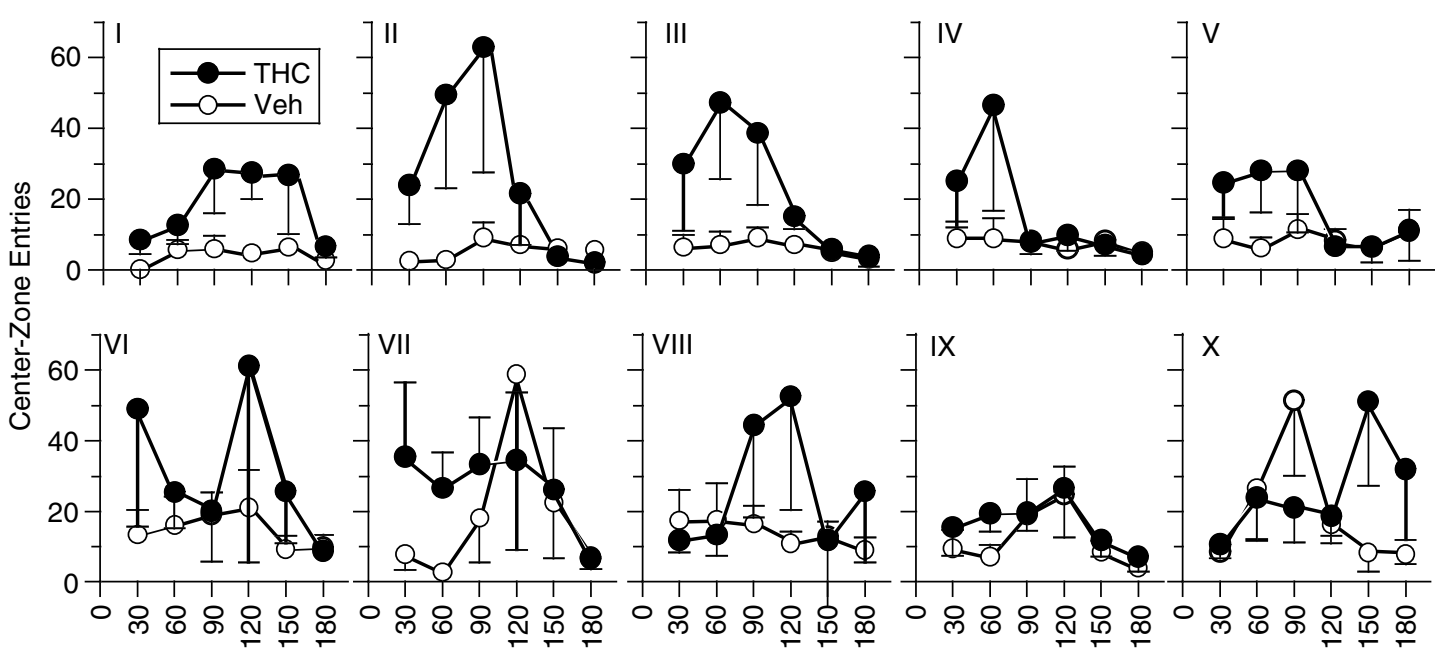

Time in Session (Minutes)

Figure 6 Center-zone entries in THC- and vehicle-exposed rats tested with heroin in Experiment 2. Mean ( \pm SEM) number of center-zone entries are shown for the same sessions depicted in Figure 5. Roman numerals: session number; Filled circles: THC-exposed; open circles: vehicle-exposed. When heroin was administered, THC-exposed rats entered the center zone significantly more than vehicle-exposed rats.
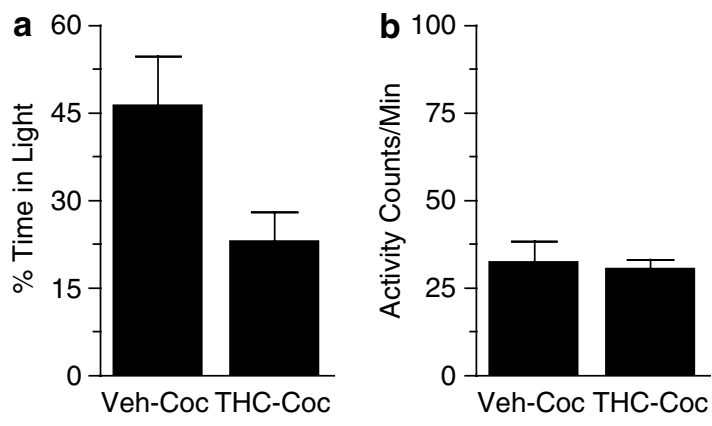

Group

Figure 7 Results from the light-dark test in the rats pre-exposed to THC or vehicle ('Veh') and tested with cocaine ('Coc') in Experiment 3. These rats were previously tested with cocaine in the locomotor chambers in Experiment 2 (data shown in Figure 4). (a) Percentage of time spent in the light compartment. The THC-exposed group spent a significantly lower percentage of time in the light compartment. (b) Locomotor activity (counts/min). This measure did not differ significantly between the two groups.

of repeatedly using or becoming addicted to either heroin or cocaine.

Comparing the present results to those obtained in earlier studies that used the same regimen of THC exposure (Cadoni et al, 2001; Solinas et al, 2004), rats pre-exposed to THC exhibited higher levels of locomotor activity than THC-naive rats when they were subsequently treated with heroin (Experiment 2 of the present study) or morphine (Cadoni et al, 2001), but not cocaine (Experiments 2 and 3 of the present study). These findings are consistent with those of studies that used different regimens of cannabinoid treatment (eg, with the cannabinoid agonist WIN55212.2) but still found enhanced levels of locomotor activity in cannabinoid-exposed rats when they were given heroin (Lamarque et al, 2001; Pontieri et al, 2001) but not cocaine (Arnold et al, 1998). These results could potentially be
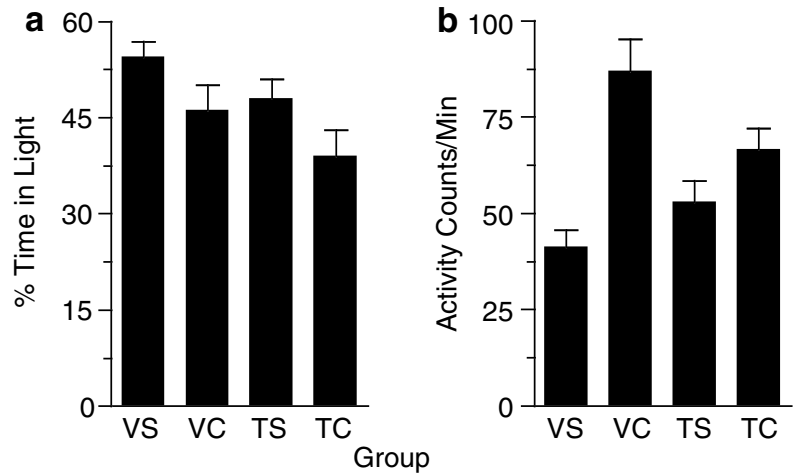

Figure 8 Results from the light-dark test in rats pre-exposed to THC ('T') or vehicle ('V') and tested with cocaine (' $C$ ') or saline ('S') in Experiment 3. These rats were tested only in Experiment 3. (a) Percentage of time spent in the light compartment. The THC-exposed group tested with cocaine spent a significantly lower percentage of time in the light compartment than the vehicle-exposed group tested with saline. (b) Locomotor activity (counts/min). Each group tested with cocaine exhibited a significantly higher level of activity than the vehicle-treated group tested with saline.

described as either cross-sensitization to the locomotoractivating effects of heroin or cross-tolerance to the locomotor-depressant effects of heroin. The present results suggest that tolerance is the more likely explanation, because THC-exposed rats exhibited higher levels of activity immediately after the heroin injection, a period in which activity is suppressed in rats that have never received THC (Amalric and Koob, 1985; Pontieri et al, 2001).

The fact that THC-exposed rats are more active following i.p. heroin administration suggests a straightforward explanation for why they also self-administer i.v. heroin at a faster rate than THC-naive rats under an FR1 schedule. Because heroin has a shorter-lived activity-suppressant effect in rats with a history of THC exposure, these rats are able to respond sooner after a self-administered injection. Drug intake under an FR1 schedule of self-administration is 
determined largely by the duration of the effect of each injection (Gerber and Wise, 1989; Panlilio et al, 2003; Tsibulsky and Norman, 1999), but drug-seeking under progressive-ratio schedules is essentially independent of duration of effect (Panlilio and Schindler, 2000; see also Ko et al, 2002). Thus, cross-tolerance to heroin's locomotorsuppressant effects would be expected to increase heroin intake under the FR1 schedule, but it should not alter the reinforcing efficacy of heroin under the progressive-ratio schedule.

THC pre-exposure had quite different effects on locomotor activity when rats were given cocaine rather than heroin. First, a history of THC exposure did not significantly alter the general locomotor activation produced by cocaine. Second, a history of THC exposure significantly decreased the number of entries into the center of the field when rats were given cocaine, an effect that suggests enhanced anxiety. Similar decreases in center-zone activity have been demonstrated in the open field with rats given anxiogenic drugs (Prut and Belzung, 2003) or electric shock (Grossen and Kelley, 1972) immediately before the test. The possibility that a history of THC exposure increases sensitivity to the anxiogenic effects of cocaine was further supported by the results obtained with the light-dark test, a procedure that has been well-validated as being sensitive to both anxiolytic and anxiogenic effects of drugs (Costall et al, 1989a; Hascoët and Bourin, 1998; Onaivi and Martin, 1989; Pich and Samanin, 1989).

Cannabinoid agonists and cocaine are both known to have effects in a variety of animal models of anxiety. McLaughlin et al (2005) found that a cannabinoid agonist decreased center-zone activity in an open field, an effect they interpreted as anxiogenic. In the elevated plus maze, cannabinoid agonists generally produce anxiogenic effects at high doses and anxiolytic effects at low doses (Arevalo et al, 2001; Berrendero and Maldonado, 2002; Marin et al, 2003; Marco et al, 2004). In the social interaction test (File, 1992; File and Seth, 2003; Genn et al, 2004) and defensive withdrawal test (Rodriguez de Fonseca et al, 1996; Yang et al, 1992), cannabinoid agonists and psychomotor stimulants can both produce anxiogenic effects. Acute administration of cocaine has been found to be anxiogenic in the light/dark test (Costall et al, 1989b), elevated plus maze (DeVries and Pert, 1998; Paine et al, 2002; Rogerio and Takahashi, 1992; Yang et al, 1992), drinking conflict test (Fontana and Commissaris, 1989), pentylenetetrazol drug discrimination (Shearman and Lal, 1981 ), and runway self-administration procedures (Ettenberg, 2004).

Although cocaine is known for its powerful reinforcing effects, its anxiogenic effects can be detected in the runway even when it is self-administered (Ettenberg and Geist, 1991, 1993; see also Spealman, 1979). In contrast, selfadministered heroin, amphetamine, and non-drug reinforcers exhibit no indication of anxiogenic effects in the runway (Ettenberg, 2004). The fact that cocaine can have both appetitive and aversive effects suggests that its reinforcing efficacy may represent the sum of these influences. Therefore, an enhancement of the anxiogenic effects of cocaine may reduce the net effectiveness of cocaine as a reinforcer in rats that have previously been exposed to THC, as indicated by testing with the progressive-ratio schedule in Experiment 1 of the present study. It should be noted that in most of the studies showing anxiogenic effects of cocaine (cited above), there was a delay of $10 \mathrm{~min}$ or more between the injection of cocaine and the beginning of the test. This fact is important because there is evidence that the reinforcing effects of cocaine are immediate (Panlilio et al, 1998), but the aversive effects are delayed (Ettenberg et al, 1999). This delay may allow cocaine to function as a reinforcer despite its aversive effects.

The results of the present study are consistent with the preponderance of evidence that cocaine has anxiogenic effects. This suggests that cocaine-induced increases in center-zone activity (Carey et al, 2005a, ) might represent a false positive for an anxiolytic effect in the open-field test. Although drugs can alter general locomotor activity and center-zone activity independently (Treit and Fundytus, 1988), in the present study there was a higher correlation between distance traveled and center-zone entries with cocaine than with heroin, suggesting that cocaine-induced increases in center-zone entries in THC-naive rats might have resulted from a general increase in locomotor activity. If so, THC exposure may have prevented cocaine from increasing center-zone entries because it enhanced cocaine's anxiogenic effects. Thus, when THC-exposed rats were given cocaine, they showed normal increases in general activity, but they avoided entering the center of the field. This avoidance may indicate either crosssensitization to the anxiogenic effects of cocaine or the summation of anxiogenic effects of prior THC exposure and acute cocaine administration.

Acute or repeated exposure to THC or other cannabinoid agonists can produce a number of alterations at the molecular, cellular, and functional levels. For example, there is evidence that chronic cannabinoid exposure alters the electrophysiological functions of rat (Hoffman et al, 2003) and mouse nucleus accumbens (Mato et al, 2005). Other studies have shown that in rats made tolerant to THC, administration of the cannabinoid antagonist rimonabant led to increased levels of corticotrophin-releasing factor in the central nucleus of the amygdala (Rodriguez de Fonseca et al, 1997), decreased levels of dopamine in the nucleus accumbens (Tanda et al, 1999), and decreased firing of dopaminergic cells in the ventral tegmental area (Diana et al, 1998). However, it should be noted that these studies were performed in vitro or used different regimens of THC exposure or different time frames to assess the consequences of THC exposure. As they mostly measured the effects of early withdrawal from THC, a time when compensating mechanisms can confound the long-lasting consequences of exposure to THC, it is not clear whether these changes may have played a role in the altered effects of cocaine we measured in this study. On the other hand, Rubino et al (2003) investigated the molecular effects of a treatment of cannabinoid agonist similar to that used in this study, measuring changes that occurred after longer withdrawal from THC. They found that exposure to the cannabinoid CB1 agonist CP 55,940 produces long-lasting changes in the number of $\mathrm{CB} 1$ receptors in the cerebellum and in the activity of $\mathrm{CB} 1$ receptors in the caudate putamen and cerebellum (Rubino et al, 2003). It is not clear at this moment whether such molecular changes are implicated in 
the alterations of cocaine's reinforcing and anxiogenic effects found in the present study.

\section{CONCLUSIONS}

With both self-administration and locomotor activity, we find that a history of THC exposure differentially affects behavior related to cocaine $v s$ heroin. These effects are long lasting, with observable differences detectable 1-2 weeks (Experiments 2 and 3) or even months (Experiment 1) after the last THC exposure. The effects of THC exposure on locomotor activity, anxiety, and self-administration of cocaine and heroin may be functionally related. In the case of heroin, THC pre-exposed rats are more active when they receive heroin, which may allow them to self-administer the next injection of heroin sooner than THC-naive rats. In the case of cocaine, THC pre-exposure appears to enhance the aversive effects of cocaine, reducing its effectiveness as a reinforcer. This potential anxiety-related interaction between THC exposure and subsequent reinforcing effects of cocaine will require further confirmation in rats (eg, using cannabinoid treatment regimens that more closely mirror various patterns of human cannabinoid use), as well as a direct evaluation of whether these effects generalize to humans. Nonetheless, these results are clearly consistent with the existing evidence that cocaine and cannabinoids can have both reinforcing and aversive effects.

\section{ACKNOWLEDGEMENTS}

This research was supported by the Intramural Research Program of the NIH, National Institute on Drug Abuse.

\section{REFERENCES}

Amalric M, Koob GF (1985). Low doses of methylnaloxonium in the nucleus accumbens antagonize hyperactivity induced by heroin in the rat. Pharmacol Biochem Behav 23: 411-415.

Arevalo C, de Miguel R, Hernandez-Tristan R (2001). Cannabinoid effects on anxiety-related behaviours and hypothalamic neurotransmitters. Pharmacol Biochem Behav 70: 123-131.

Arnold JC, Topple AN, Hunt GE, McGregor IS (1998). Effects of pre-exposure and co-administration of the cannabinoid receptor agonist CP 55,940 on behavioral sensitization to cocaine. Eur J Pharmacol 354: 9-16.

Arnold JM, Roberts DC (1997). A critique of fixed and progressive ratio schedules used to examine the neural substrates of drug reinforcement. Pharmacol Biochem Behav 57: 441-447.

Baumrind D (1983). Specious causal attributions in the social sciences: the reformulated stepping-stone theory of heroin use as exemplar. J Pers Soc Psychol 45: 1289-1298.

Berrendero F, Maldonado R (2002). Involvement of the opioid system in the anxiolytic-like effects induced by Delta(9)tetrahydrocannabinol. Psychopharmacology 163: 111-117.

Cadoni C, Pisanu A, Solinas M, Acquas E, Di Chiara G (2001). Behavioural sensitization after repeated exposure to Delta 9tetrahydrocannabinol and cross-sensitization with morphine. Psychopharmacology 158: 259-266.

Caille S, Parsons LH (2003). SR141716A reduces the reinforcing properties of heroin but not heroin-induced increases in nucleus accumbens dopamine in rats. Eur J Neurosci 18: 3145-3149.

Carey RJ, DePalma G, Damianopoulos E (2005a). Evidence for Pavlovian conditioning of cocaine-induced responses linked to emotional behavioral effects. Pharmacol Biochem Behav 80: 123-134.

Carey RJ, DePalma G, Damianopoulos E (2005b). Acute and chronic cocaine behavioral effects in novel versus familiar environments: open-field familiarity differentiates cocaine locomotor stimulant effects from cocaine emotional behavioral effects. Behav Brain Res 158: 321-330.

Cossu G, Ledent C, Fattore L, Imperato A, Bohme GA, Parmentier $M$ et al (2001). Cannabinoid CB1 receptor knockout mice fail to self-administer morphine but not other drugs of abuse. Behav Brain Res 118: 61-65.

Costall B, Jones BJ, Kelly ME, Naylor RJ, Tomkins DM (1989a). Exploration of mice in a black and white test box: validation as a model of anxiety. Pharmacol Biochem Behav 32: 777-785.

Costall B, Kelly ME, Naylor RJ, Onaivi ES (1989b). The actions of nicotine and cocaine in a mouse model of anxiety. Pharmacol Biochem Behav 33: 197-203.

DeVries AC, Pert A (1998). Conditioned increases in anxiogeniclike behavior following exposure to contextual stimuli associated with cocaine are mediated by corticotropin-releasing factor. Psychopharmacology 137: 333-340.

DeVries TJ, Homberg JR, Binnekade R, Raas $\varnothing$ H, Schoffelmeer ANM (2003). Cannabinoid modulation of the reinforcing and motivational properties of heroin and heroin-associated cues in rats. Psychopharmacology 168: 164-169.

Diana M, Melis M, Muntoni AL, Gessa GL (1998). Mesolimbic dopaminergic decline after cannabinoid withdrawal. Proc Natl Acad Sci USA 95: 10269-10273.

Ellickson PL, Hays RD, Bell RM (1992). Stepping through the drug use sequence: longitudinal scalogram analysis of initiation and regular use. J Abnorm Psychol 101: 441-451.

Ettenberg A (2004). Opponent process properties of self-administered cocaine. Neurosci Biobehav Rev 27: 721-728.

Ettenberg A, Geist TD (1991). Animal model for investigating the anxiogenic effects of self-administered cocaine. Psychopharmacology 103: 455-461.

Ettenberg A, Geist TD (1993). Qualitative and quantitative differences in the operant runway behavior of rats working for cocaine and heroin reinforcement. Pharmacol Biochem Behav 44: 191-198.

Ettenberg A, Raven MA, Danluck DA, Necessary BD (1999). Evidence for opponent-process actions of intravenous cocaine. Pharmacol Biochem Behav 64: 507-512.

Fattore L, Martellotta MC, Cossu G, Mascia MS, Fratta W (1999). CB1 cannabinoid receptor agonist WIN 55,212-2 decreases intravenous cocaine self-administration in rats. Behav Brain Res 104: 141-146.

Fergusson DM, Horwood LJ (2000). Does cannabis use encourage other forms of illicit drug use? Addiction 95: 505-520.

File SE (1992). Behavioural detection of anxiolytic action. In: Elliot JM, Heal DJ, Marsden CA (eds). Experimental Approaches to Anxiety and Depression. Wiley: New York. pp 25-44.

File SE, Seth P (2003). A review of 25 years of the social interaction test. Eur J Pharmacol 463: 35-53.

Fontana DJ, Commissaris RL (1989). Effects of cocaine on conflict behavior in the rat. Life Sci 45: 819-827.

Genn RF, Tucci S, Marco EM, Viveros MP, File SE (2004). Unconditioned and conditioned anxiogenic effects of the cannabinoid receptor agonist CP 55,940 in the social interaction test. Pharmacol Biochem Behav 77: 567-573.

Gerber GJ, Wise RA (1989). Pharmacological regulation of intravenous cocaine and heroin self-administration in rats: a variable dose paradigm. Pharmacol Biochem Behav 32: 527-531.

Gorriti MA, Ferrer B, del Arco I, Bermudez-Silva FJ, de Diego Y, Fernandez-Espejo E et al (2005). Acute delta9-tetrahydrocannabinol exposure facilitates quinpirole-induced hyperlocomotion. Pharmacol Biochem Behav 81: 71-77. 
Gorriti MA, Rodriguez de Fonseca F, Navarro M, Palomo T (1999). Chronic (-)-delta9-tetrahydrocannabinol treatment induces sensitization to the psychomotor effects of amphetamine in rats. Eur J Pharmacol 365: 133-142.

Griffiths RR, Findley JD, Brady JV, Dolan-Gutcher K, Robinson WW (1975). Comparison of progressive-ratio performance maintained by cocaine, methylphenidate and secobarbital. Psychopharmacologia 43: 81-83.

Grossen NE, Kelley MJ (1972). Species-specific behavior and acquisition of avoidance behavior in rats. J Comp Physiol Psychol 81: 307-310.

Hascoët M, Bourin M (1998). A new approach to the light/dark test procedure in mice. Pharmacol Biochem Behav 60: 645-653.

Hoffman AF, Oz M, Caulder T, Lupica CR (2003). Functional tolerance and blockade of long-term depression at synapses in the nucleus accumbens after chronic cannabinoid exposure. J Neurosci 23: 4815-4820.

Kandel D, Faust R (1975). Sequence and stages in patterns of adolescent drug use. Arch Gen Psychiat 32: 923-932.

Kandel D (1975). Stages in adolescent involvement in drug use. Science 190: 912-914.

Kandel DB (2003). Does marijuana use cause the use of other drugs? J Am Med Assoc 289: 482-483.

Ko MC, Terner J, Hursh S, Woods JH, Winger G (2002). Relative reinforcing effects of three opioids with different durations of action. J Pharmacol Exp Ther 301: 698-704.

Lamarque S, Taghzouti K, Simon H (2001). Chronic treatment with Delta(9)-tetrahydrocannabinol enhances the locomotor response to amphetamine and heroin. Implications for vulnerability to drug addiction. Neuropharmacology 41: 118-129.

Lynskey MT, Heath AC, Bucholz KK, Slutske WS, Madden PA, Nelson EC et al (2003). Escalation of drug use in early-onset cannabis users vs co-twin controls. J Am Med Assoc 289: 427-433.

Marco EM, Perez-Alvarez L, Borcel E, Rubio M, Guaza C, Ambrosio E et al (2004). Involvement of 5-HT1A receptors in behavioural effects of the cannabinoid receptor agonist $\mathrm{CP}$ 55,940 in male rats. Behav Pharmacol 15: 21-27.

Marin S, Marco E, Biscaia M, Fernandez B, Rubio M, Guaza C et al (2003). Involvement of the kappa-opioid receptor in the anxiogenic-like effect of CP 55,940 in male rats. Pharmacol Biochem Behav 74: 649-656.

Martin M, Ledent C, Parmentier M, Maldonado R, Valverde O (2000). Cocaine, but not morphine, induces conditioned place preference and sensitization to locomotor responses in CB1 knockout mice. Eur J Neurosci 12: 4038-4046.

Mato S, Robbe D, Puente N, Grandes P, Manzoni OJ (2005). Presynaptic homeostatic plasticity rescues long-term depression after chronic Delta9-tetrahydrocannabinol exposure. J Neurosci 25: 11619-11627.

McLaughlin PJ, Lu D, Winston KM, Thakur G, Swezey LA, Makriyannis A et al (2005). Behavioral effects of the novel cannabinoid full agonist AM 411. Pharmacol Biochem Behav 81: 78-88.

Moreno M, Lopez-Moreno JA, Rodriguez de Fonseca F, Navarro M (2005). Behavioural effects of quinpirole following withdrawal of chronic treatment with the CB1 agonist, HU-210, in rats. Behav Pharmacol 16: 441-446.

National Research Council (2003). Guidelines for the Care and Use of Mammals in Neuroscience and Behavioral Research. National Academics Press: Washington, DC.

Navarro M, Carrera MR, Fratta W, Valverde O, Cossu G, Fattore L et al (2001). Functional interaction between opioid and cannabinoid receptors in drug self-administration. J Neurosci 21: $5344-5350$.

Norwood CS, Cornish JL, Mallet PE, McGregor IS (2003). Preexposure to the cannabinoid receptor agonist CP 55,940 enhances morphine behavioral sensitization and alters morphine self-administration in Lewis rats. Eur J Pharmacol 465: 105-114. Onaivi ES, Martin BR (1989). Neuropharmacological and physiological validation of a computer-controlled two-compartment black and white box for the assessment of anxiety. Prog Neuro-Psychopharmacol Biol Psychiat 13: 963-976.

Paine TA, Jackman SL, Olmstead MC (2002). Cocaine-induced anxiety: alleviation by diazepam, but not buspirone, dimenhydrinate or diphenhydramine. Behav Pharmacol 13: 511-523.

Panlilio LV, Goldberg SR, Gilman JP, Jufer R, Cone EJ, Schindler CW (1998). Effects of delivery rate and non-contingent infusion of cocaine on cocaine self-administration in rhesus monkeys. Psychopharmacology 137: 253-258.

Panlilio LV, Katz JL, Pickens RW, Schindler CW (2003). Variability of drug self-administration in rats. Psychopharmacology 167: 9-19.

Panlilio LV, Schindler CW (2000). Self-administration of remifentanil, an ultra-short acting opioid, under continuous and progressive-ratio schedules of reinforcement in rats. Psychopharmacology 150: 61-66.

Pich EM, Samanin R (1989). A two-compartment exploratory model to study anxiolytic/anxiogenic effects of drugs in the rat. Pharmacol Res 21: 595-602.

Pontieri FE, Monnazzi P, Scontrini A, Buttarelli FR, Patacchioli FR (2001). Behavioral sensitization to heroin by cannabinoid pretreatment in the rat. Eur J Pharmacol 421: R1-R3.

Prut L, Belzung C (2003). The open field as a paradigm to measure the effects of drugs on anxiety-like behaviors: a review. Eur $J$ Pharmacol 463: 3-33.

Ramos A, Correia EC, Izidio GS, Bruske GR (2003). Genetic selection of two new rat lines displaying different levels of anxiety-related behaviors. Behav Genet 33: 657-668.

Ramos A, Mellerin Y, Mormede P, Chaouloff F (1998). A genetic and multifactorial analysis of anxiety-related behaviours in Lewis and SHR intercrosses. Behav Brain Res 96: 195-205.

Rodriguez de Fonseca F, Carrera MRA, Navarro M, Koob GF, Weiss F (1997). Activation of corticotropin-releasing factor in the limbic system during cannabinoid withdrawal. Science 276: 2050-2054.

Rodriguez de Fonseca F, Rubio P, Menzaghi F, Merlo-Pich E, Rivier J, Koob GF et al (1996). Corticotropin-releasing factor (CRF) antagonist [D-Phe12,Nle21,38,C alpha MeLeu37]CRF attenuates the acute actions of the highly potent cannabinoid receptor agonist HU-210 on defensive-withdrawal behavior in rats. J Pharmacol Exp Ther 276: 56-64.

Rogerio R, Takahashi RN (1992). Anxiogenic properties of cocaine in the rat evaluated with the elevated plus-maze. Pharmacol Biochem Behav 43: 631-633.

Rubino T, Vigano D, Massi P, Parolaro D (2003). Cellular mechanisms of Delta 9-tetrahydrocannabinol behavioural sensitization. Eur J Neurosci 17: 325-330.

Shearman GT, Lal H (1981). Discriminative stimulus properties of cocaine related to an anxiogenic action. Prog Neuropsychopharmacol 5: 57-63.

Solinas M, Panlilio LV, Antoniou K, Pappas LA, Goldberg SR (2003). The cannabinoid CB1 antagonist $\mathrm{N}$-piperidinyl-5-(4chlorophenyl)-1-(2,4-dichlorophenyl)-4-methylpyrazole-3-car boxamide (SR-141716A) differentially alters the reinforcing effects of heroin under continuous reinforcement, fixed ratio, and progressive ratio schedules of drug self-administration in rats. J Pharmacol Exp Ther 306: 93-102.

Solinas M, Panlilio LV, Goldberg SR (2004). Exposure to delta-9tetrahydrocannabinol (THC) increases subsequent heroin taking but not heroin's reinforcing efficacy: a self-administration study in rats. Neuropsychopharmacology 29: 1301-1311.

Solinas M, Panlilio LV, Tanda G, Makriyannis A, Matthews SA, Goldberg SR (2005). Cannabinoid agonists but not inhibitors of endogenous cannabinoid transport or metabolism enhance the 
reinforcing efficacy of heroin in rats. Neuropsychopharmacology 30: 2046-2057.

Soria G, Mendizabal V, Tourino C, Robledo P, Ledent C, Parmentier $M$ et al (2005). Lack of CB1 cannabinoid receptor impairs cocaine self-administration. Neuropsychopharmacology 30: $1670-1680$.

Spealman RD (1979). Behavior maintained by termination of a schedule of self-administered cocaine. Science 204: 1231-1233.

Stafford D, LeSage MG, Glowa JR (1998). Progressive-ratio schedules of drug delivery in the analysis of drug selfadministration: a review. Psychopharmacology 139: 169-184.

Tanda G, Loddo P, Di Chiara G (1999). Dependence of mesolimbic dopamine transmission on delta9-tetrahydrocannabinol. Eur $J$ Pharmacol 376: 23-26.
Tanda G, Munzar P, Goldberg SR (2000). Self-administration behavior is maintained by the psychoactive ingredient of marijuana in squirrel monkeys. Nat Neurosci 3: 1073-1074.

Treit D, Fundytus M (1988). Thigmotaxis as a test for anxiolytic activity in rats. Pharmacol Biochem Behav 31: 959-962.

Tsibulsky VL, Norman AB (1999). Satiety threshold: a quantitative model of maintained cocaine self-administration. Brain Res 839: 85-93.

Vendruscolo LF, Takahashi RN, Bruske GR, Ramos A (2003). Evaluation of the anxiolytic-like effect of NKP608, a NK1receptor antagonist, in two rat strains that differ in anxietyrelated behaviors. Psychopharmacology 170: 287-293.

Yang XM, Gorman AL, Dunn AJ, Goeders NE (1992). Anxiogenic effects of acute and chronic cocaine administration: neurochemical and behavioral studies. Pharmacol Biochem Behav 41: 643-645. 